\title{
Modeling of Dielectric Barrier Discharge Plasma Actuator
}

\author{
Balaji Jayaraman*, Young-Chang Cho ${ }^{* *}$ and Wei Shyy ${ }^{* * *}$ \\ Department of Aerospace Engineering \\ University of Michigan, Ann Arbor, MI 48109
}

Glow discharge at atmospheric pressure using a dielectric barrier discharge can induce fluid flow, and operate as an actuator for flow control. In this paper, we simulate the physics of a 2-D asymmetric actuator operating in Helium gas using a high-fidelity first principles-based numerical modeling approach to help improve our understanding of the physical mechanisms associated with such actuators. Fundamentally, there are two processes in the two half-cycles of the actuator operation, largely due to the difference in mobility between faster electrons and slower ions, and the geometric configurations of the DBD/electrodes. The first half-cycle is characterized by the deposition of the slower ion species on the insulator surface while the second half-cycle by the deposition of the electrons at a faster rate. A power-law (cubic) dependence on the voltage for the resulting force is observed, which indicates that larger force can be generated by increasing the amplitude. Furthermore, one can enhance the effectiveness of the actuator, by either increasing the peak value of the periodic force generation or by increasing the asymmetry between the voltage half-cycles or both. Overall, the increase in the lower electrode size, applied voltage and dielectric constant tends to contribute to the first factor, and the decrease in frequency of applied voltage tends to contribute to the second factor. However, the complex interplay between the above factors determines the actuator performance.

$\begin{array}{llll}\mathrm{n} \text { or } \mathrm{N} & =\text { Particle number density } & \mathrm{e} & =\text { Electron charge } \\ \mathrm{v} & =\text { Particle velocity } & \varepsilon_{0} & =\text { Permittivity of free space } \\ \phi & =\text { Electric potential } & \varepsilon_{\mathrm{d}}, \varepsilon_{\text {gas }} & \begin{array}{l}\text { Relative permittivities of dielectric } \\ \text { material and gas }\end{array} \\ \mathbf{E} & =\text { Electric field vector }=\left(\mathrm{E}_{\mathrm{x}}, \mathrm{E}_{\mathrm{y}}\right) & \mathrm{k} & =\text { Boltzmann constant } \\ \mathrm{F}_{\mathrm{x}} & =\text { Domain averaged } \mathrm{x} \text {-directional force } & \varepsilon_{\mathrm{k}} & =\text { Internal energy density } \\ \mathrm{F}_{\mathrm{x}, \text { avg }} & =\text { Time averaged } \mathrm{F}_{\mathrm{x}} \text { over one cycle } & \mathrm{f}_{\mathrm{v}} & =\text { Frequency of applied voltage } \\ \mathrm{m} & =\text { Particle mass } & \mathrm{V}_{\mathrm{app}} & =\text { Magnitude of applied voltage } \\ \mathrm{D} & =\text { Diffusivity of charged particles } & \mu & =\text { Mobility of charged particles } \\ \mathrm{p} & =\text { Gas pressure } & \mathrm{S}_{\mathrm{ie}} & =\text { Ionization rate } \\ \text { Kn } & =\text { Knudsen number }=\frac{\text { mean free path }(\lambda)}{\text { flow length scale }(\mathrm{L})} & \mathrm{R} & =\text { Recombination rate } \\ \text { Subscript } & =\text { Ion, electron } & & \end{array}$

\section{Introduction}

Glow discharge at atmospheric pressure using a dielectric barrier discharge can induce fluid flow and operate as an actuator for flow control [1-6]. The largely isothermal surface plasma generation realized above can modify the near-wall flow structure by means of Lorentzian collisions between the ionized fluid and the neutral fluid. Such an actuator has advantages of no moving parts, performance at atmospheric conditions and devising complex control strategies through the applied voltage. However, the mechanism of the momentum coupling between the plasma and the fluid flow is not yet adequately understood which has fostered in recent times, a flurry of computational research activity towards deciphering the operating mechanisms and attempts to improve the present designs. Numerous applications including separation control [1], aerodynamic noise reduction [9] and surface heat transfer enhancement [5] have been adopted widely in the context of both low speed as well as high

\begin{tabular}{ll}
\hline$*$ & Research Fellow \\
$* *$ & Graduate Student \\
$* * *$ & Clarence L. "Kelly" Johnson Collegiate Professor and Chair
\end{tabular}


speed flow applications [10,11]. A schematic illustration of an asymmetric actuator arrangement altering the nearwall flow is shown in Figure 1.

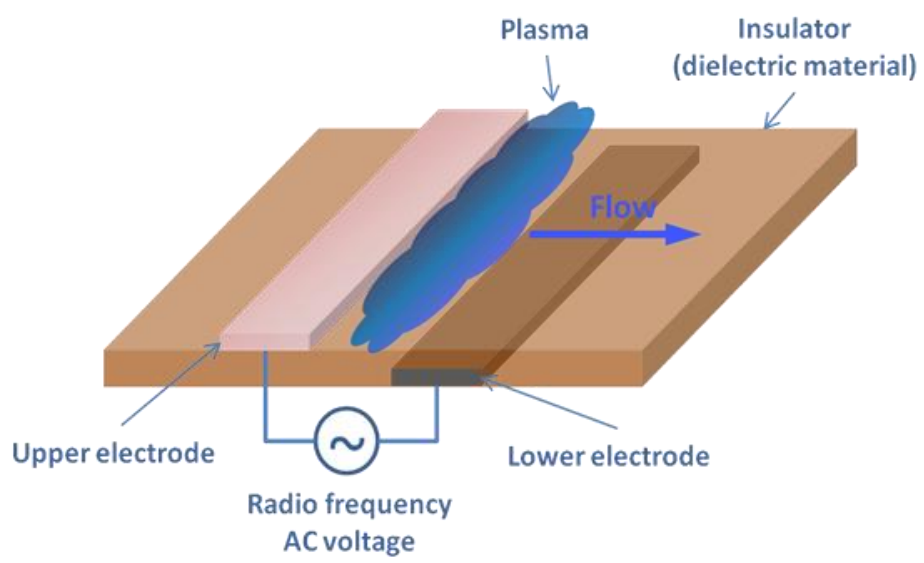

Figure 1. Illustration of glow discharge and induced flow

Although these research studies indicate a wide range of application, the flow induced by the plasma actuator remains applicable predominantly in the low speed region. Even with various attempts with diverse geometries and applied voltages, the maximum flow velocity in the region of $5 \mathrm{~m} / \mathrm{s}$ with $10 \mathrm{kV}$ applied voltage for a single electrode pair although with peristaltic arrangements [14], an array of single actuators, the induced flow achieves an order of magnitude increase. Improving the performance with minimal power is important to broaden the application scope of the plasma actuator. These actuators typically operate on low power consumption (2-40W/ft of wing span from [16]) with the capability to be operated either in a continuous or pulsed fashion. It is reported [16] that the unsteady, pulsed actuation of the discharge results in $90 \%$ less power consumption as compared to a steady actuation.

In the parametric investigations of a single actuator, Van Dyken et al. [17] mention the waveform shape and dielectric thickness as the primary parameters affecting performance. Distinguishing the one atmosphere uniform glow discharge plasma (OAUGDP) and the dielectric barrier discharge (DBD), Roth et al. state that the efficiency of producing plasma can be maximized at the Stoletow point (it is the point at which ionization happens with minimum energy requirement) in which a uniform, large volume plasma is realized [18]. It has been documented [16] that the power approximately varies as the cube of applied voltage, but the induced flow saturates at higher voltages when the discharge transitions from a weakly-ionized to the corona/streamer mode. The performance of the actuator is also heavily dependent on the choice of dielectric material: quartz and Teflon ${ }^{\circledR}$ are known to produce the highest induced flow velocity with the least input power. Pons et al. [19] in their experimental work analyze the impact of the voltage frequency and magnitude along with the dielectric material thickness and conclude that a higher permittivity results in a higher velocity and larger power consumption.

In order to enhance the efficiency of the plasma actuator, it is important to investigate the DBD operating parameters by examining the dominant physical mechanisms. First-principle based modeling of the detailed plasma dynamics in conjunction with the low-speed fluid dynamics has been developed by the present authors [6] and in other parallel efforts [12, 35-37]. Computationally, the combined discharge physics and thermo-fluid transport modeling is a challenging problem due to the multiple nonlinear partial differential equations with strong source terms, and widely distributed length and time scales. The disparate length and time scales make the system computationally stiff, often requiring that numerical simulations be conducted with very small time-step sizes [6]. Previously, a simpler model which is phenomenological in nature has been devised [1,5], where the approach is based on a linear field solution satisfying the governing equations with the model parameter being closed by observed experimental data. This model has been employed in many recent modeling studies such as [26]. In order to offer a more comprehensive predictive capability, the present paper offers a refined treatment by accounting for the plasma physics based on the first principles approach to establish correlations between the actuator performance and the design parameters. Similar efforts have also been undertaken [35-37], which complement our approach. Since there is insufficient experimental evidence to validate the computational models, cross evaluations between the various studies are needed. In particular, the present approach is based on a different numerical framework, but 
the modeling parameters and transport property variations have been adopted from Roy et al [35-37]. Furthermore, we offer more probing of the interplay between the DBD operating parameters and the performance outcome.

Specifically, we present the numerical results for the 2-D asymmetric actuator ((b) Top half of the domain indicating boundary conditions for plasma species and the region where the results are presented.

Figure 2), operating in helium gas, using the governing equations and the modeling approach summarized in the following sections. Following this, the performance of the actuator in terms of the net force generation is investigated by varying the operating parameters/design configurations such as applied voltage, frequency, geometry, input voltage waveform etc.

\section{Numerical Model}

\section{Plasma-fluid model}

The fluid model for modeling the DBD consists of the first few moments of the Boltzmann equation for the various species with a near-Maxwellian distribution function. The plasma is considered as a multi-component fluid comprised of two types of primary species, namely, ions and electrons (represented by subscripts 'i' and 'e', respectively).

\section{Continuity equation}

$\begin{array}{ll}\text { Electrons: } & \frac{\partial \mathrm{n}_{\mathrm{e}}}{\partial \mathrm{t}}+\nabla \cdot\left(\mathrm{n}_{\mathrm{e}} \mathrm{v}_{\mathrm{e}}\right)=\mathrm{n}_{\mathrm{e}} \mathrm{S}_{\mathrm{ie}}-\mathrm{rn}_{\mathrm{i}} \mathrm{n}_{\mathrm{e}} \\ \text { Ions: } & \frac{\partial \mathrm{n}_{\mathrm{i}}}{\partial \mathrm{t}}+\nabla \cdot\left(\mathrm{n}_{\mathrm{i}} \mathrm{v}_{\mathrm{i}}\right)=\mathrm{n}_{\mathrm{e}} \mathrm{S}_{\mathrm{ie}}-\mathrm{rn}_{\mathrm{i}} \mathrm{n}_{\mathrm{e}}\end{array}$

Here, the source terms on the right hand side represent the reaction/ionization processes which result in the creation (S) or destruction ( $r$ ) of the species, as applicable.

Momentum equation

The momentum equation for the species at high pressures can be reduced to the drift-diffusion form which neglects the inertial and unsteady terms and balances the thermodynamic pressure gradient with the drift force and collision terms.

Electrons:

Ions:

$$
\begin{aligned}
& \mathrm{n}_{\mathrm{e}} \mu_{\mathrm{e}} \mathbf{E}-\nabla\left(\mathrm{n}_{\mathrm{e}} \mathrm{D}_{\mathrm{e}}\right)=\mathrm{n}_{\mathrm{e}} \mathrm{v}_{\mathrm{e}} \\
& \mathrm{n}_{\mathrm{i}} \mu_{\mathrm{i}} \mathbf{E}-\nabla\left(\mathrm{n}_{\mathrm{i}} \mathrm{D}_{\mathrm{i}}\right)=\mathrm{n}_{\mathrm{i}} \mathrm{v}_{\mathrm{i}} \text { (for high-pressure discharges) }
\end{aligned}
$$

As long as the thermal velocity is comparable to the drift velocity and we are in the continuum regime ( $\frac{\lambda}{\mathrm{L}}=\mathrm{Kn} \ll$ 1 ), the inertial components in the momentum equation can be neglected. What is realized is a balance between the collision/ionization effects and the drift-diffusion components.

The electric field equation

The electric field $\mathbf{E}$ is obtained using the solution of the Poisson equation, given by

\section{Solution algorithm}

$$
\nabla \cdot\left(\varepsilon_{\mathrm{d}} \mathbf{E}\right)=\frac{\mathrm{e}\left(\mathrm{n}_{\mathrm{i}}-\mathrm{n}_{\mathrm{e}}\right)}{\varepsilon_{0}}
$$

The above set of equations is solved using a predictor-corrector type approach for enhanced coupling between the dependent variables. The multiple scales arising from the ionized species chemistry are treated using a semi-implicit method for source terms. Specifically, an operator-split algorithm is embedded as part of a projection method to enhance coupling between the various species equations being solved. The detailed description of the solution approach is presented in [6,7].

It is noted that for the low-speed, i.e., incompressible, fluid flow applications, which is the current focus, the fluid characteristic time-scales are much larger than that of the operating plasma dynamics. For example, for an airfoil of $15 \mathrm{~cm}$ chord, at the Reynolds number of $10^{4}$, the convective time scale is $\mathrm{O}\left(10^{-1}\right)$ if one considers air as the fluid. In comparison, for a DBD device at $10 \mathrm{kHz}$ the period is $\mathrm{O}\left(10^{-4}\right)$. Hence, we can safely treat the coupling between the fluid and plasma physics as one-way, i.e. from the plasma to the fluid by means of the body force model. To extend further, if the fluid dynamic time-scales become comparable, then the two-way coupling will need to be handled and the fluid solution advancement should be performed using the DBD time-scale.

\section{Results and Discussion}

In this section, we will model the two-dimensional radio frequency dielectric barrier discharge (DBD) in helium gas at high pressure in an asymmetric configuration as shown in Figure 2. The electrodes are $2 \mathrm{~mm}$ in length and the insulated bottom electrode is shifted downstream by $2 \mathrm{~mm}$. A similar case has been studied by Roy et al.[35- 
37]. The helium discharge is modeled at a pressure of 300 torr and a temperature of $300 \mathrm{~K}$ and is driven by an AC voltage of $1 \mathrm{kV}$ (peak voltage) operating at $5 \mathrm{kHz}$. The thickness of the electrodes is negligible and the dielectric thickness is $5 \mathrm{~mm}$. The electron temperature is assumed to be $1 \mathrm{eV}(\sim 11600 \mathrm{~K})$, while the ions and the neutrals are essentially in thermal equilibrium at $300 \mathrm{~K}$.

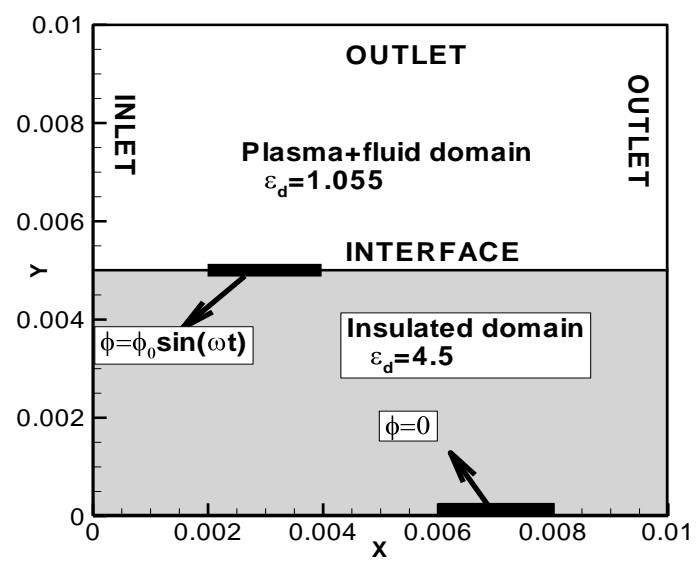

(a) Complete domain with insulator indicating boundary conditions for fluid flow

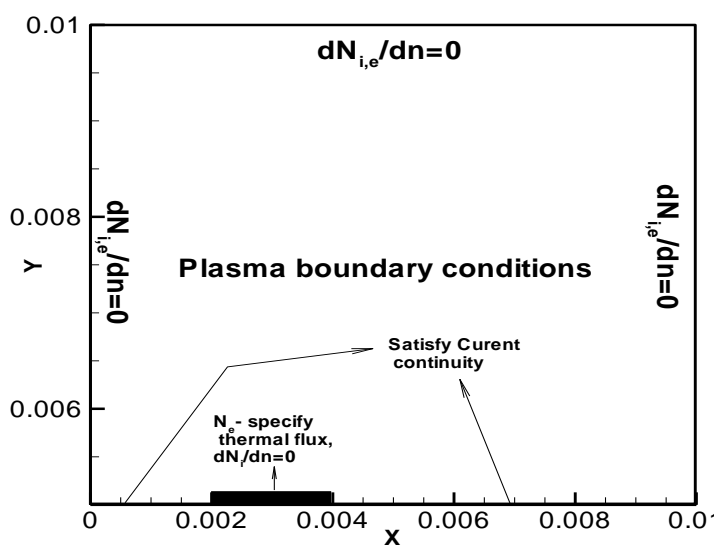

(b) Top half of the domain indicating boundary conditions for plasma species and the region where the results are presented.

Figure 2. A representative 2-D asymmetric discharge arrangements

The computational domain employed is a square domain of size $1 \mathrm{~cm} \times 1 \mathrm{~cm} \times 1 \mathrm{~cm}$ (unit $\mathrm{cm}$ in the spanwise direction). The grid consists of 127 x 61 points for the 2-D case as is shown in Figure 2b. The dielectric constant in the fluid/discharge domain is 1.0055; the permittivity of vacuum and that of the insulator is varied between 1 and 30 . For investigation purposes, the frequency is varied from $5 \mathrm{kHz}$ through $30 \mathrm{kHz}$, with all other conditions remaining constant. A global integration time-step of $10^{-8} \mathrm{~s}$ is used for the computations. The initial number density in the plasma is $10^{15} / \mathrm{m}^{3}$ for all the different species.

The various transport properties and property relationships are available in literature and we will use the ones used by Roy et al.[ 35] for the present study. These are summarized in Table 1.

\section{Boundary conditions}

The boundary conditions are schematically presented in Figure $2 \mathrm{~b}$. The homogeneous Neumann boundary condition is applied for the electrostatic potential at the open boundaries while the Dirichlet boundary condition is used at the electrode:

At the exposed electrode: $\Phi=\Phi_{0} \operatorname{Sin}(2 \pi \mathrm{ft})$, where $\Phi_{0}$ is the peak value.

At the submerged electrode: $\Phi=0$ 
For the plasma species modeling, the domain boundary away from the insulator/electrode surface is assigned a zero normal gradient condition assuming insignificant impact far away from the fluid-actuator interface. At the dielectric surface, the drift current and the displacement current from the gas domain is balanced with the displacement current inside the insulator. At the electrode, the treatment is slightly different. The electrons are assumed to be isothermal (at $11600 \mathrm{~K}$ or $1 \mathrm{eV}$ ) at boundaries. At the exposed electrode, the thermal flux towards the wall is considered while it is neglected when the drift is away from the wall. For the ions or the heavier species, the drift effects are significant and hence a zero gradient condition $\left(\frac{\partial \mathrm{n}_{\mathrm{i}}}{\partial \mathrm{n}}=0\right)$ is applied. The boundary conditions are summarized in Table 2.

Table 1. Summary of property models employed for the He discharge simulation.

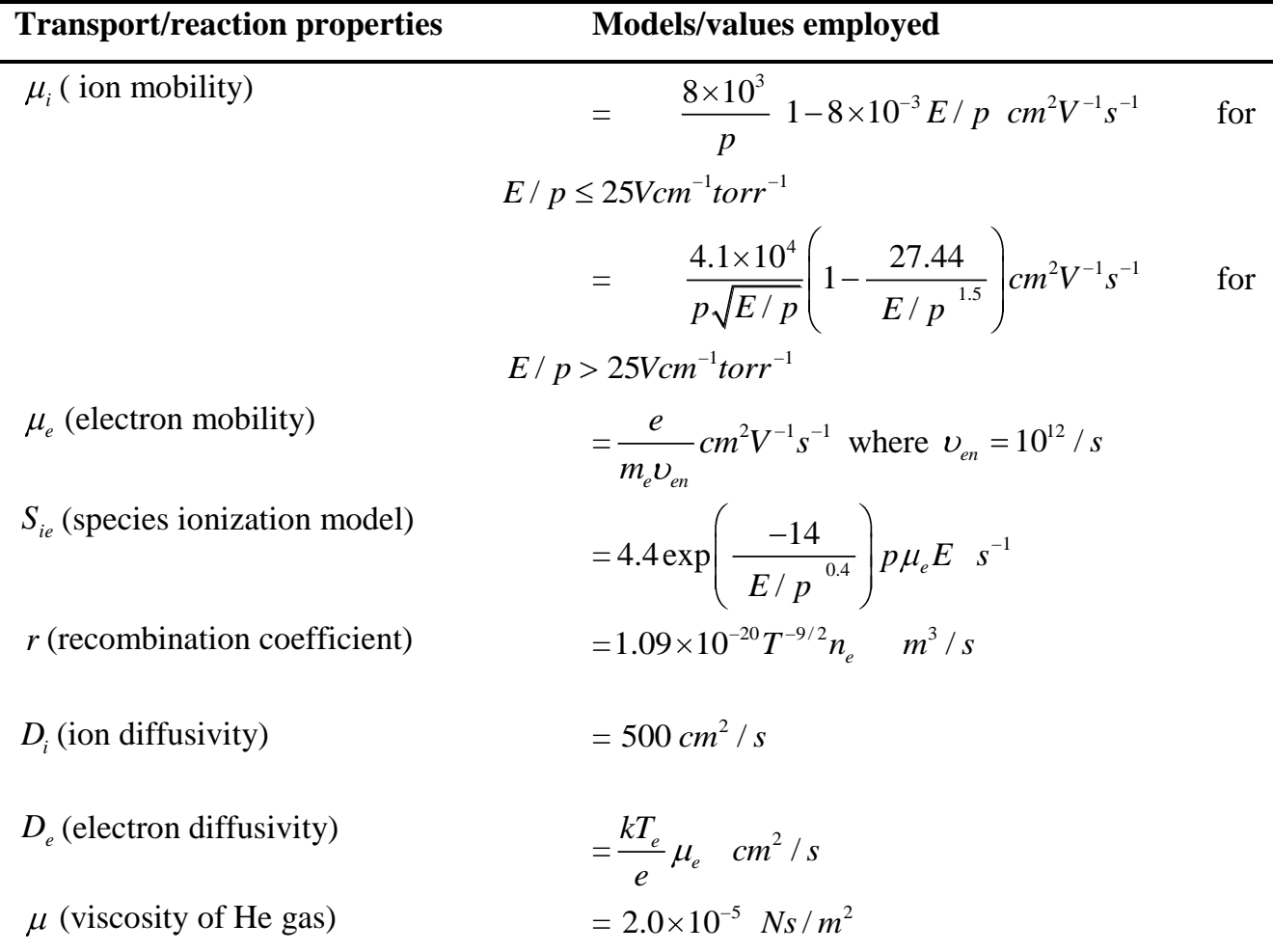

Note: Data presented are the same used in [35].

Plasma species initial condition

The initial condition used to start the simulation requires specifying the starting number densities for the various species. Ideally the simulation should start from a very small charge concentration, but to accelerate the evolution of the transient behavior to a periodic steady state solution we will use a weakly preionized neutral concentration of $10^{9} / \mathrm{cm}^{3}$. Our simulations reveal that the dynamics of the operating discharge plasma actuator is only a function of the difference in the values of $\left(\mathrm{n}_{\mathrm{i}}-\mathrm{n}_{\mathrm{e}}\right)$ or more generally the net charge in the region. It is observed that the periodic steady state solution is attained much quicker with a starting guess of $10^{9} / \mathrm{cm}^{3}$ and is used as the initial condition for the results presented here.

\section{Plasma Structure}

In the following discussion we will analyze the discharge structure evolution in space and time for helium gas, generated in an asymmetric configuration as described in Figure 2. The numerical simulation shown is for $1 \mathrm{kV}$ and $5 \mathrm{kHz}$ applied sinusoidal voltage waveform. 
Table 2. Summary of boundary conditions for the different variables

\begin{tabular}{|c|c|c|}
\hline Variable & Open boundary & Electrode/dielectric surface \\
\hline$\phi$-potential & Zero gradient & $\begin{array}{l}\text { At the submerged electrode: } \Phi=0 \\
\text { At the exposed electrode: } \Phi=\Phi_{0} \operatorname{Sin}(2 \pi \mathrm{ft}), \Phi_{0}=1 \mathrm{kV} \\
\text { The dielectric is not a boundary for the potential. }\end{array}$ \\
\hline $\begin{array}{l}\text { Electron,Ion } \\
\text { species }\end{array}$ & Zero gradient & $\begin{array}{l}\text { Electrode: } \\
\text { Electrons: } \\
\text { Away from the electrode: flux }=0 \\
\text { If drift is toward the electrode: flux }=\mathrm{n}_{\mathrm{e}} \mathrm{v}_{\mathrm{eth}} \text {, where } \mathrm{v}_{\mathrm{eth}} \text { is the } \\
\text { thermal velocity. } \\
\text { Ions: } \\
\text { Away from the electrode: flux }=0 \\
\text { If drift is toward the electrode: zero gradient } \\
\frac{\text { On the dielectric: }}{\text { Allow surface charge accumulation. To do this the current }} \\
\text { continuity is established. i.e. At the dielectric-gas interface the } \\
\text { species flux is determined by } \\
\frac{\partial\left(\varepsilon_{\text {gas }} \mathrm{E}_{\text {gas }}\right)}{\partial \mathrm{t}}+\frac{\mathrm{e}}{\varepsilon_{0}}\left(\mathrm{n}_{\mathrm{i}} \mathrm{v}_{\mathrm{i}}-\mathrm{n}_{\mathrm{e}} \mathrm{v}_{\mathrm{e}}\right)_{\text {gas }}=\frac{\partial\left(\varepsilon_{\text {dielectric }} \mathrm{E}_{\text {dielectric }}\right)}{\partial \mathrm{t}}\end{array}$ \\
\hline
\end{tabular}

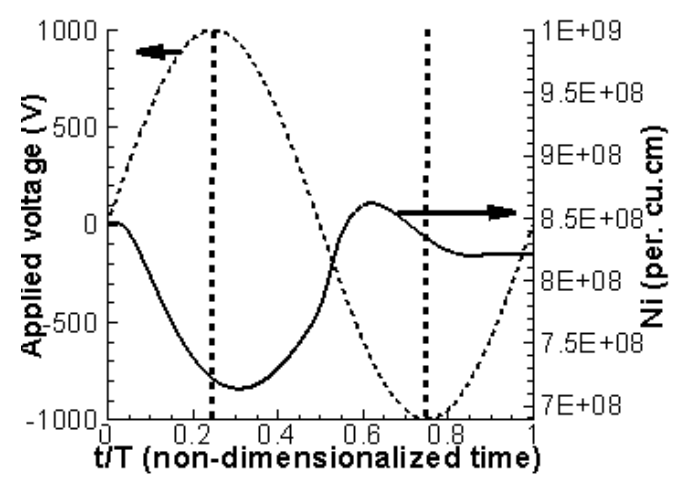

(a) Input voltage signal and Domainaveraged ion charge density

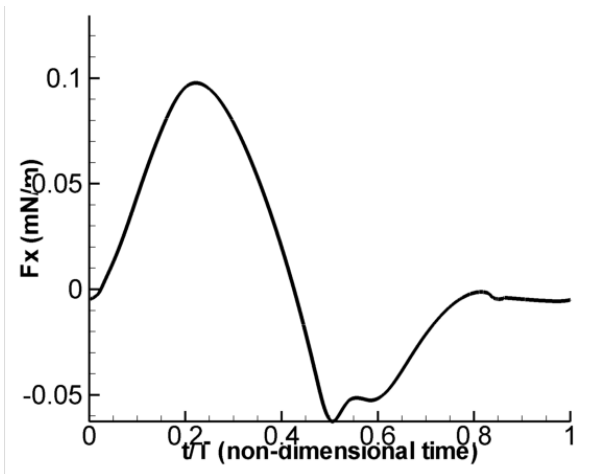

(c ) $F_{x}$ history

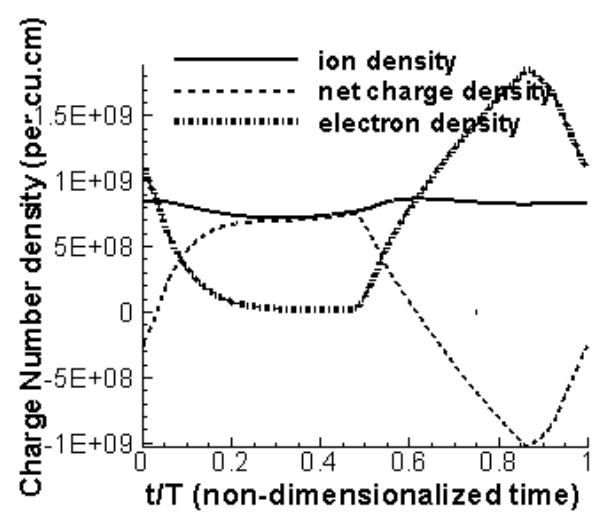

(b) Domain-averaged species charge density and net charge density variation

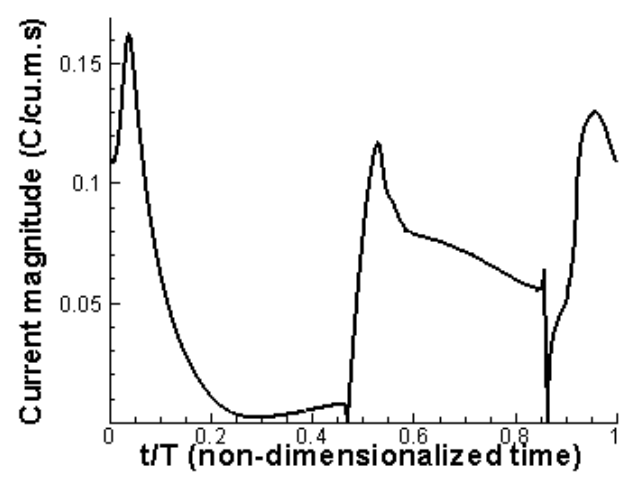

(d) Absolute value of discharge current calculated

Figure 3. Time dependent plasma behavior for one time cycle ( $5 \mathrm{KHz}, 1 \mathrm{KV}$ applied voltage)

Self-limiting Discharge: It is common knowledge that the breakdown is quenched and controlled by the accumulated charge since the discharge terminates on a dielectric surface, resulting in the self-limiting nature of the discharge. 
This can be observed from the experimental observations in [4] where a continuously varying applied voltage is necessary to sustain the discharge. Here, the light intensity observed is zero as soon as the observed potential reaches either maxima or minima. This phenomenon can be observed in the numerical results as well. Figure $3 \mathrm{a}$ and $\mathrm{b}$ show the mean density variation in time for the different species and the net charge density. It is known that in the positive half-cycle the ions move away from the electrode and tend to get deposited on the surface. Hence the decrease in the average ion density over the domain as the averaging process doesn't account for the surface deposition. Similar to the experimental observation this decrease in ion density is stopped when the increase in voltage is zero near the maxima. This can be clearly seen in the evolution of the ion density in the domain as shown in Figure 4.

Specifically in the first quarter of the actuator-cycle as can be seen in instants A, B and C, the ion concentration increases near the dielectric surface and the free concentration in the domain at its minimum. At instants D, E and F, the applied voltage starts decreasing, causing the built-up potential from the accumulation to dominate resulting in releasing the ion species into the bulk region. The ion density reaches its maximum value between instants $\mathrm{F}$ and $\mathrm{G}$. At this point the change in polarity enhances the release of ions which travel towards the negative exposed electrode. However, there is no ion build-up during this part of the cycle as the electrode being a conductor absorbs the incoming charge flux. Before the instant I, Figure 4a shows the ion number density as stabilizing due to the equilibrium attained between the absorption at the electrode and the accumulated ion release from the insulator surface. This behavior continues for the rest of the cycle.

Force variation: The domain averaged force variation in time presented in Figure 5a shows that the positive-half cycle has a predominantly positive force, while the negative half-cycle has both positive and negative components. This is clearly seen from the evolution of the force field over time as shown in Figure 5b. It is well known that the bulk of the momentum transfer is achieved by the heavier ion species ion species in the domain. As can be seen from Figure $4 \mathrm{~b}$, the positive half-cycle corresponding to instants A,B,C,D and E correspond to the accumulation of ion species on the insulator surface from the bulk of the domain. Since the submerged electrode is downstream, the bulk of the transport in this half is in the positive direction and to a lesser extent in the negative direction. Hence the strong positive force regions near the insulator surface downstream of the electrode and a weaker component upstream of the electrode for instants A,B,C and D as seen in Figure 5b. Starting from instant E at which time the charge build-up reverses the polarity of the potential in the region. This happens for a half cycle corresponding to instants $\mathrm{E}$ and $\mathrm{F}$ during which the weak negative force region near the downstream insulator surface exits due to the ion transport towards the upstream electrode. An interesting phenomenon happens at this instant in the cycle. It should be noted that during this half that the electrons are the species which get accumulated on the dielectric surface resulting in the charge build-up. However, the electrons being lighter species travel faster and hence the faster charge build-up and a quicker reversal of polarity in the domain.

There is the qualitative similarity between the instants G,H, I and B,C,D in Figure 5b, but the process is only more quicker. The above mechanism renders the force weaker in this negative half, as the discharge is quenched early. This force generation efficiency throughout one cycle is of importance here as the slower response time of the fluid will only see the net overall force generation over a few time-cycles and is less sensitive to the fluctuation over time.

Asymmetry in the discharge: The above discussion on the time evolution of the force field indicates two different processes in the two half-cycles. The first half-cycle shows a pure ionization and deposition of the slower ion species on the insulator surface while the second half-cycle shows the faster deposition of electrons with the same mechanism. This difference in the mobilities of the two species and the geometric asymmetry affects the discharge evolution in the second half-cycle. This asymmetry can be observed in the experimental measurements [4] as well. 


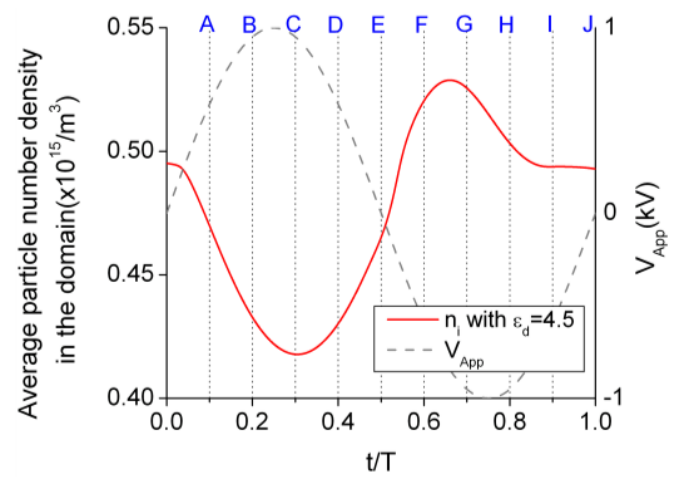

(a) Domain-averaged ion number density over time.

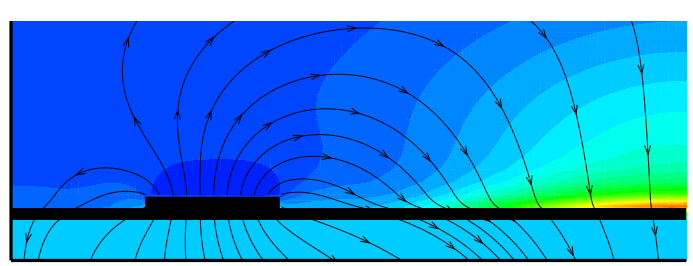

A

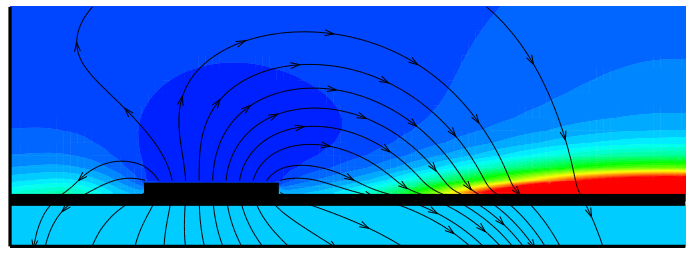

C

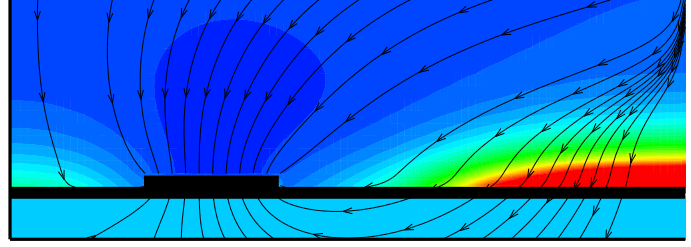

$\mathrm{E}$

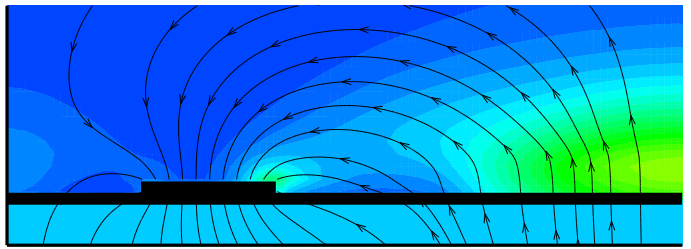

$\mathrm{G}$

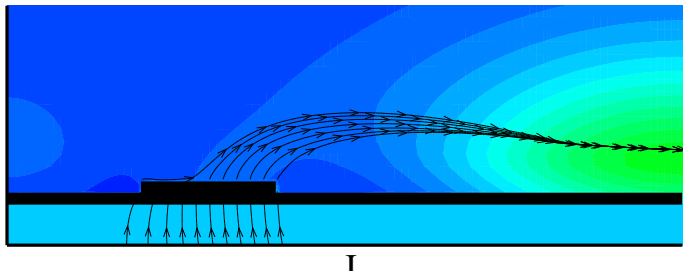

(b) Instantaneous snapshots of the ion density at different instants over a cycle.

Figure 4. Ion density evolution in the domain over one time cycle $(5 \mathrm{kHz}, 1 \mathrm{kV}$ applied voltage) 


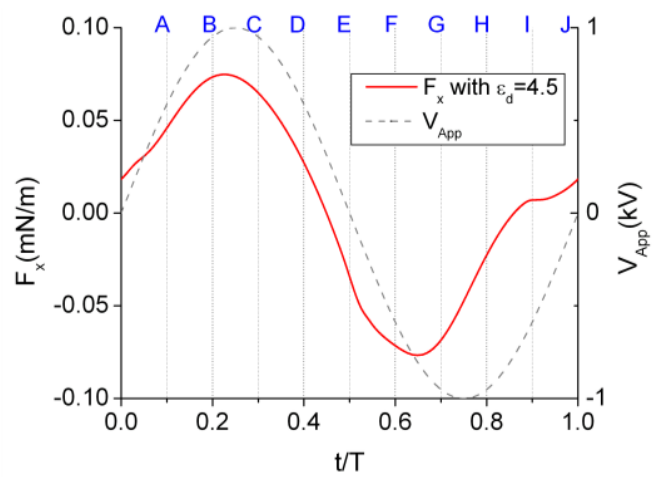

(a) Domain averaged $\mathrm{x}$-directional force $\left(\mathrm{F}_{\mathrm{x}}\right)$ variation in time

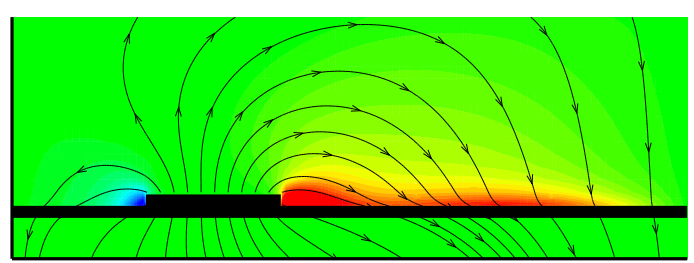

A

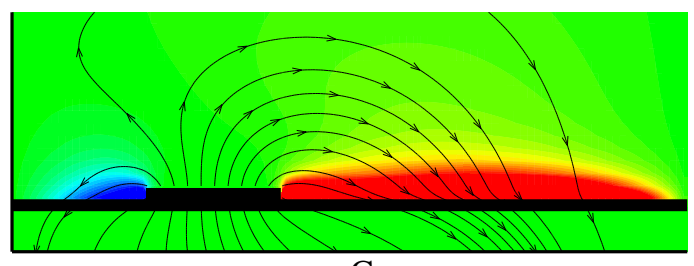

$\mathrm{C}$

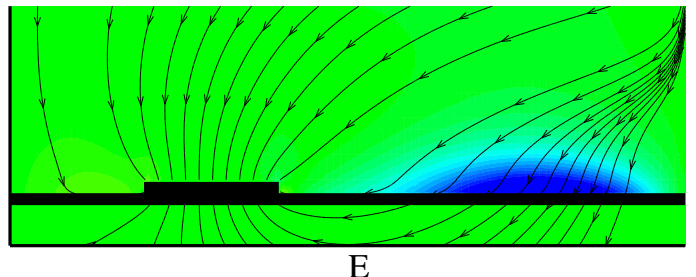

$\mathrm{E}$

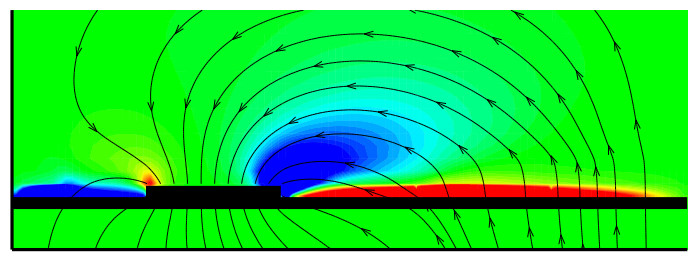

G

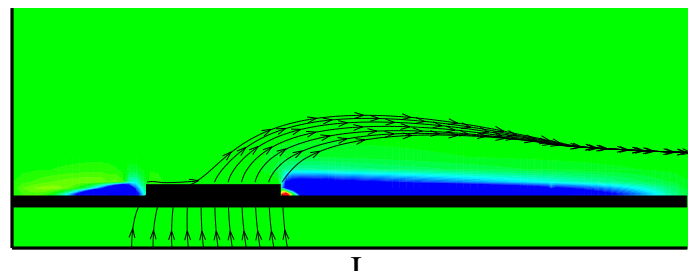

(b) Instantaneous snapshots of the $F_{x}$ field at different instants over a cycle.

Figure 5. Force evolution over one time cycle $(5 \mathrm{kHz}, 1 \mathrm{kV}$ applied voltage)
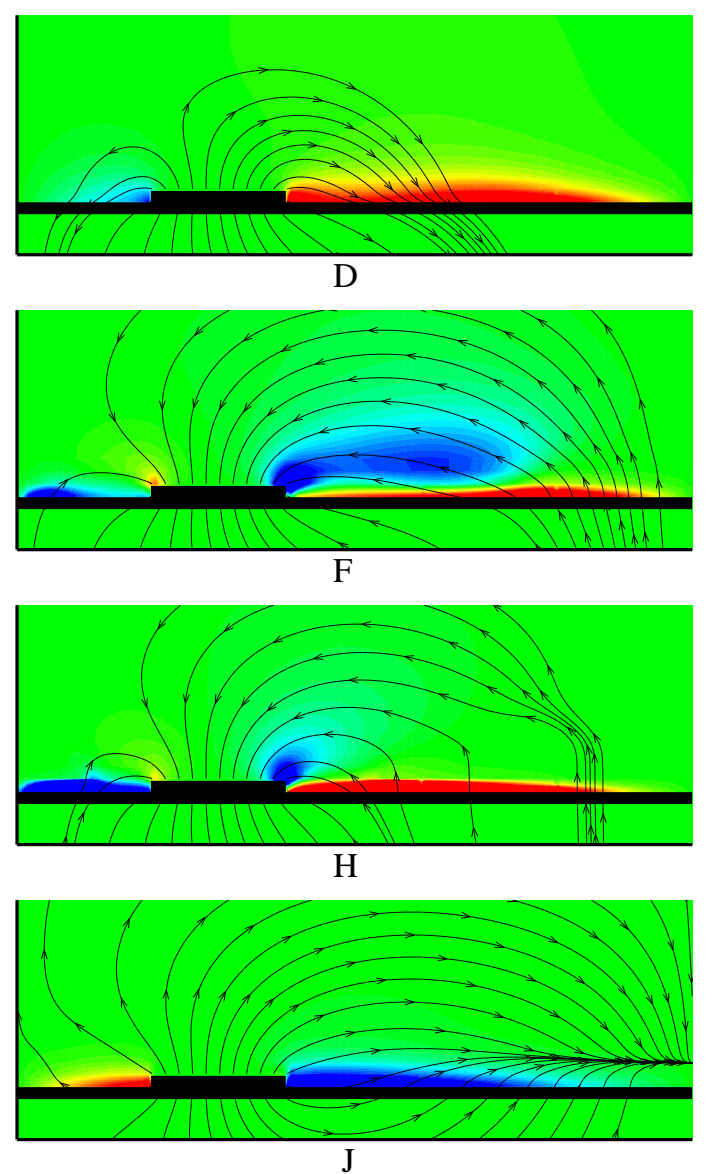


\section{Geometric Effects}

Impact of lower electrode size

Here we fix the length of the top electrode and vary the bottom electrode to gauge the impact of the area covered the by the net surface discharge formation. The actuator operates using a $20 \mathrm{kHz}, 0.4 \mathrm{kV}$ sinusoidal voltage waveform. Figure 7 and Table 3 indicate that the weakest force field is obtained for the $2 \mathrm{~mm}$ electrode case while there is steady increase in the net force value as the size of the bottom electrode increases. This effect is because the larger lower electrode obviously results in a much larger surface discharge generation and hence the stronger force field. However, once the lower electrode becomes sufficiently large, a balance between size and strength will be reached signifying the most efficient configuration. Similar trends have been observed by experimental studies such as by Enloe et al.[4].
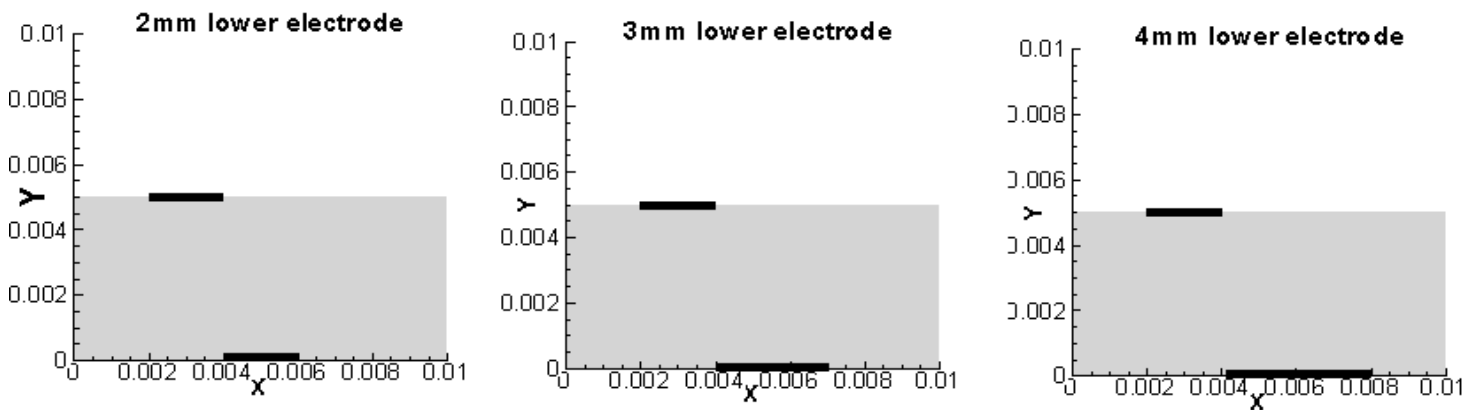

Figure 6. Three different lower electrode lengths modeled to investigate the effect of increased surface area on the discharge

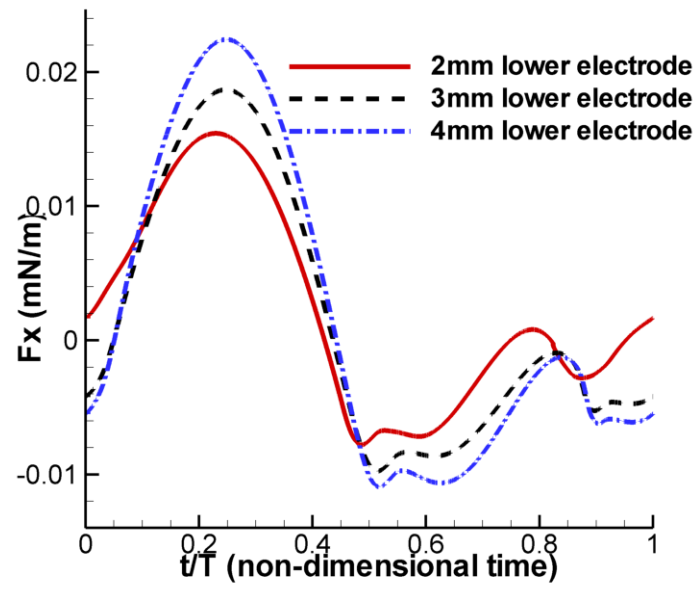

Figure 7. Impact of lower electrode size

Table 3. Force dependence on the lower electrode size

\begin{tabular}{cc}
\hline Lower electrode size $(\mathbf{m m})$ & $\mathbf{F}_{\mathbf{x}, \mathbf{a v g}}(\mathbf{m N} / \mathbf{m})$ \\
\hline 2 & 0.00023 \\
3 & 0.00065 \\
4 & 0.0010 \\
\hline
\end{tabular}

\section{Effects of Applied Voltage}

Impact of Waveform

The observed behavior for the harmonic waveform indicated that the positive going half (irregular) had a different discharge characteristic as compared to the negative going half (uniform discharge) leading to the asymmetry which causes the uni-directional momentum coupling with the fluid flow. Also, in the earlier discussion the positive sawtooth waveform has a much faster positive-going and a slower negative going cycle. The negative sawtooth has a faster negative going and slower positive going cycle. 


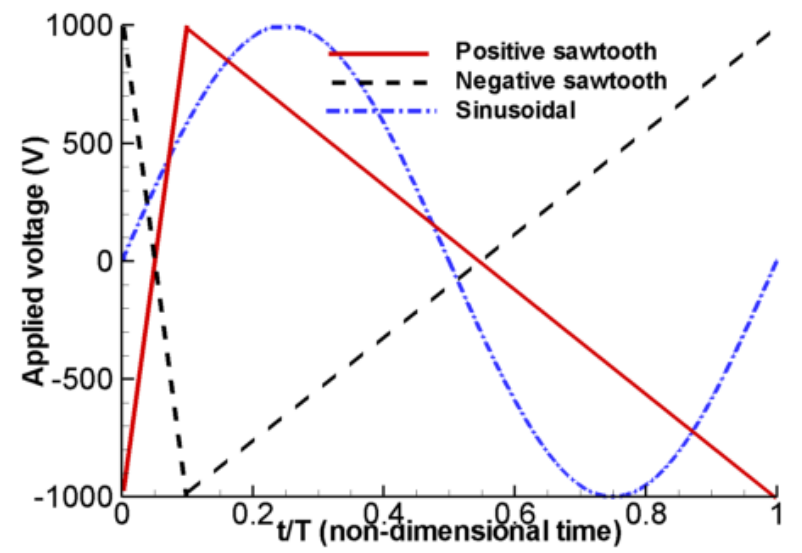

Figure 8. Different input asymmetric sawtooth voltage signals $(1 \mathrm{kV}, 10 \mathrm{kHz})$ used in the numerical study.

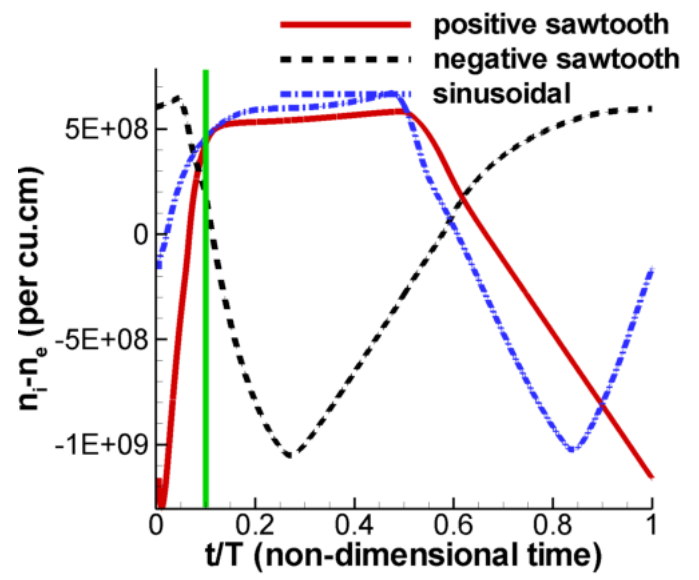

Figure 9. Impact of waveform on the net species charge number density

Enloe et al. [4] measure the thrust produced by the actuator for both of the above sawtooth waveforms using a mass balance to assess efficiency of the two half-cycles. The positive sawtooth has a faster varying positive going voltage and a slower varying negative going voltage and vice versa for the negative sawtooth. The result in [4] clearly shows that the positive sawtooth is more efficient compared to the negative sawtooth waveform. This is because unlike the light intensity measurements, the force orientation tends to depend heavily on the geometric asymmetry and hence strongly dependent on the polarity of the exposed and the submerged electrodes. On the other hand the magnitude of the force is a function of the strength of the discharge and charge concentration available in the domain. The positive sawtooth has a stronger positive going part which results in a strong breakdown while the negative sawtooth has a stronger negative going part. One can infer from the force response to the harmonic waveform (Figure 5a) that the positive going part (exposed electrode is positive) is possibly more efficient than the negative going part. The domain-averaged force responses for the sawtooth waveforms are shown in Figure 10. The force for the positive and negative sawtooth waveforms starts the time-cycle in the similar fashion with negative slope. For the negative sawtooth, the force continues on its negative slope and attains a negative peak during the fast varying early phase (negative-going voltage) and then steadily increases to a positive value during the slow-varying positive-going phase. The harmonic waveform seems to be the most efficient waveform. The negative sawtooth is the least efficient with the positive sawtooth falling in between. The force profile over time indicates that the positive going phase is the most efficient part of the voltage cycle for the asymmetric actuator modeled in this study.

Table 4. Domain averaged force over the voltage cycle for different waveforms

\begin{tabular}{lc}
\hline Waveform & $\mathbf{F}_{\mathbf{x}, \mathbf{a v g}}(\mathbf{m N} / \mathbf{m})$ \\
\hline Positive sawtooth & 0.0068 \\
Negative Sawtooth & 0.0063 \\
Sinusoidal & 0.0081 \\
\hline
\end{tabular}

11

American Institute of Aeronautics and Astronautics 


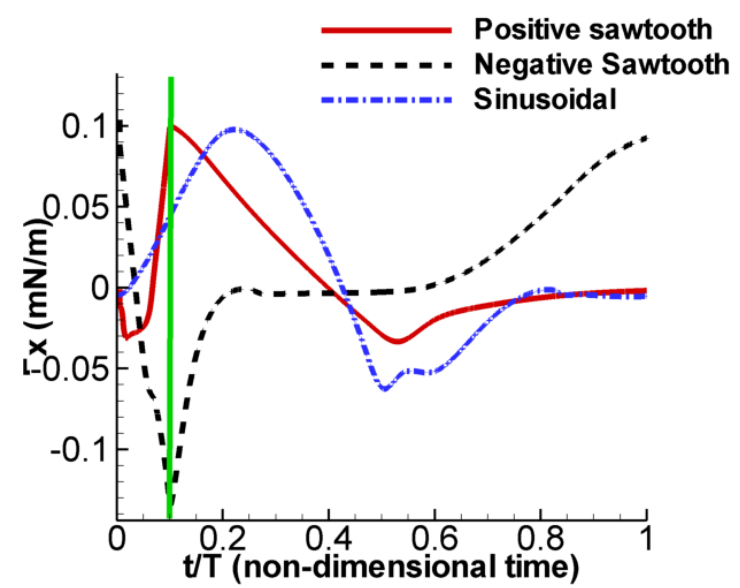

Figure 10. Domain averaged $F_{x}$ with time for different waveforms $(10 \mathrm{kHz}, 1 \mathrm{kV}$ applied voltage). The green vertical line indicates the instant of change in slope in the sawtooth waveform.

\section{Impact of Frequency}

The effect of frequency with different dielectric constant is presented in Figure 11. The increase in the frequency of applied voltage basically induces the increase and delay in the negative force generation which significantly decreases the time-averaged force generation even to the negative sign.

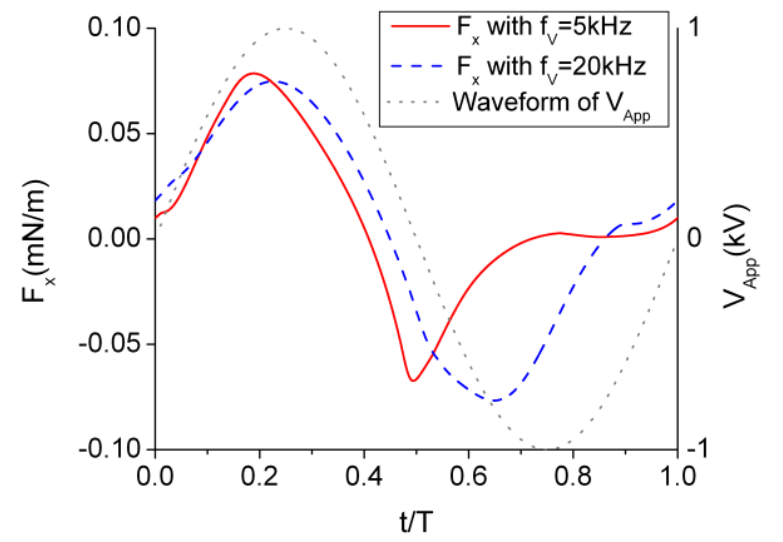

a) $\varepsilon_{\mathrm{d}}=4.5$

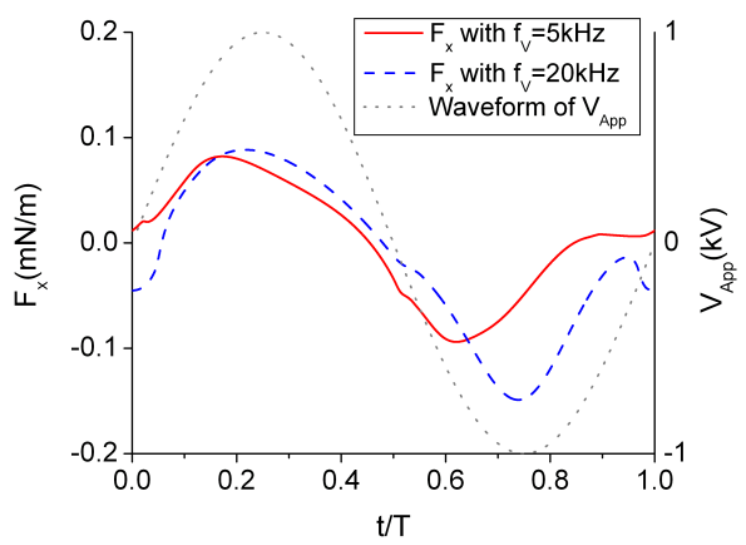

b) $\varepsilon_{\mathrm{d}}=30$

Figure 11. Frequency effect for different dielectric constant

In general, the increased frequency induces lower amount of charged particles since the time in which the electric field is sufficient enough to ionize particles is shorter, which means less ionization as in Figure 12. In the same reason the case with lower frequency shows faster electron accumulation on the surface in the normalized time coordinate which results in the faster saturation as in Figure 13, although the actual growth rate of electron numbers in the case of higher frequency is similar to or higher than the lower one differently from the normalized time result. The time-varying pseudo-electrode which is the region of the accumulated electrons is affected by the number of accumulated electrons at each time and can significantly affect the electric field for the following half cycle when their accumulation is prominent. 


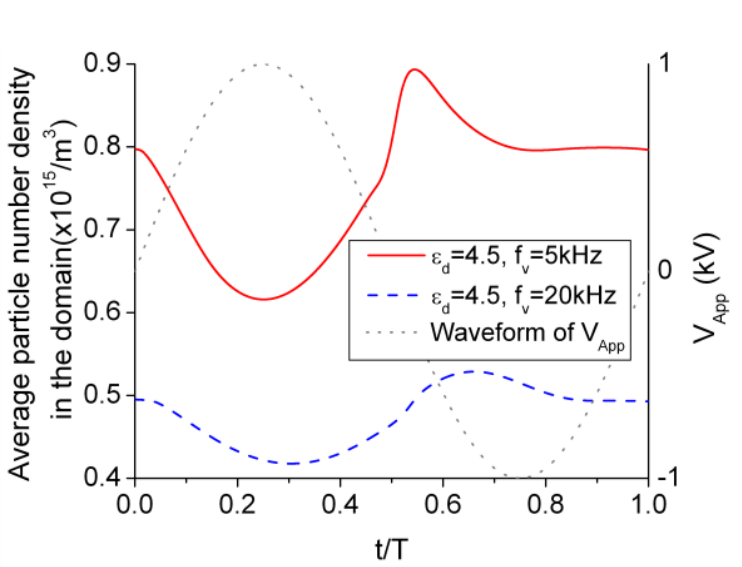

a) $\varepsilon_{\mathrm{d}}=4.5$

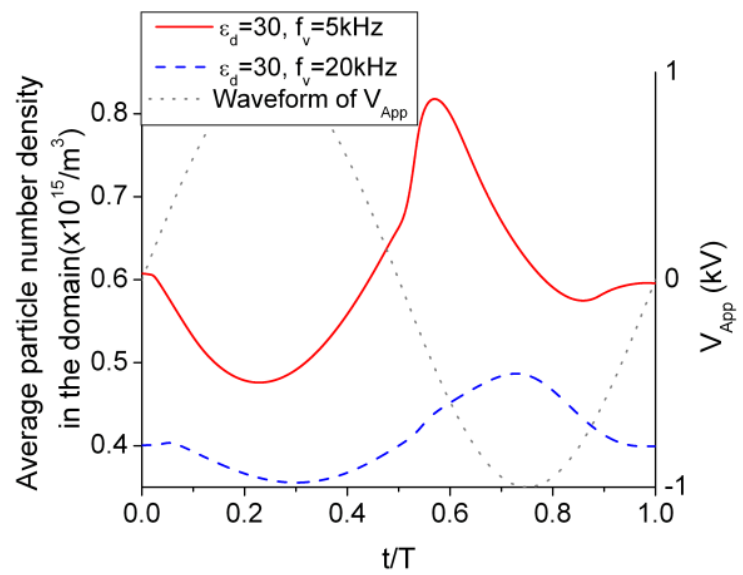

b) $\varepsilon_{d}=30$

Figure 12. Domain averaged ion number density

Comparing Figure 11 with Figure 13, it is evident that the saturation of electron accumulation is responsible for the restriction of negative force generation. However if the saturation is allowed to happen nearly at the end of the second cycle as $f_{v}=20 \mathrm{kHz}$ in Figure $13 \mathrm{~b}$ ), a drop in $\mathrm{F}_{\mathrm{x}}$ before the next positive cycle may occur as in Figure $11 \mathrm{~b}$ ), which also contributes to bias the average force to decrease. With the increased frequency of the applied voltage, this pseudo-electrode with negative charge remains weaker, compensates less of the electric field near the surface compared to the lower frequency, and as a result produces higher magnitude of the negative force in the second half cycle. As a result, increased frequency results in decrease in time and domain averaged force, $F_{x, a v g}$ as in Table 5.

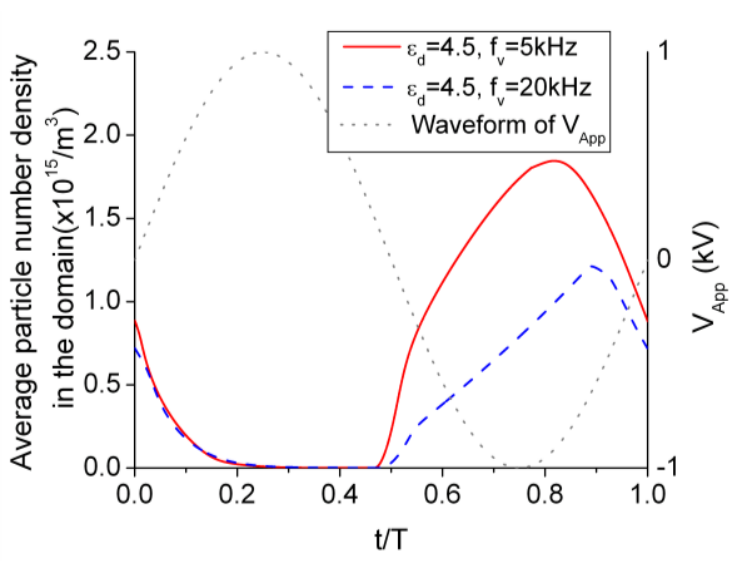

a) $\varepsilon_{\mathrm{d}}=4.5$

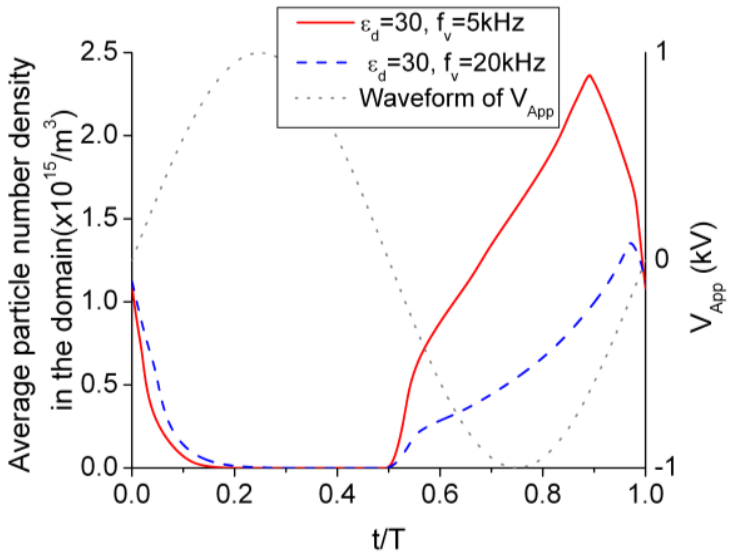

b) $\varepsilon_{\mathrm{d}}=30$

Figure 13. Domain averaged electron number density

Table 5. Domain averaged force over the voltage cycle for different frequencies

\begin{tabular}{ll}
\hline Frequency $(\mathbf{k H z})$ & $\mathbf{F}_{\mathbf{x}, \text { avg }}(\mathbf{m N} / \mathbf{m})$ \\
\hline 20 & 0.0059 \\
10 & 0.0095 \\
5 & 0.0125 \\
\hline
\end{tabular}

Impact of Voltage Magnitude

The net charge density and $F_{x}$ history is presented in Figure 14 and $F_{x, a v g}$ in Table 6 with various magnitude of applied voltage. 


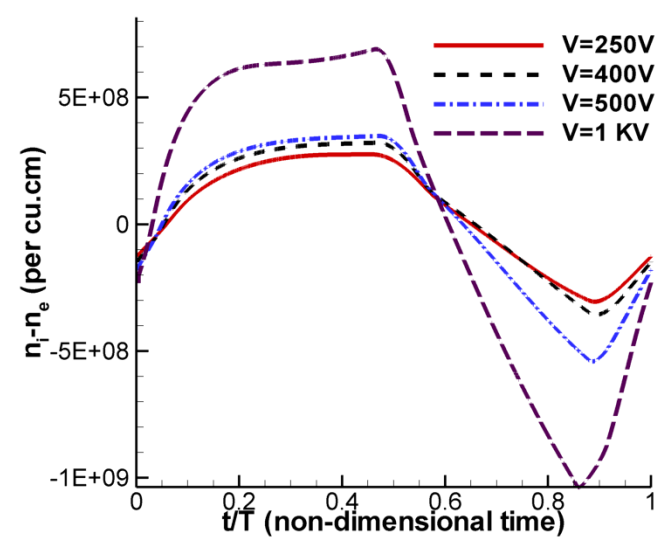

(a) Averaged Net charge density

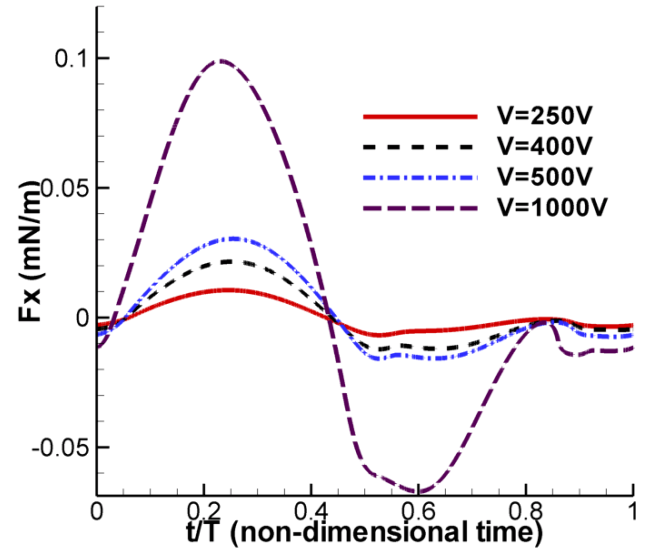

(b) Averaged horizontal force component

Figure 14. Charge density and force variation over time for different voltages $\left(20 \mathrm{kHz}\right.$ of frequency, $\left.\varepsilon_{\mathrm{d}}=4.5\right)$

Table 6. Mean domain averaged force over the time cycle for different voltage

\begin{tabular}{lc}
\hline Voltage $(\mathbf{V})$ & $\mathbf{F}_{\mathbf{x}, \text { avg }}(\mathbf{m N} / \mathbf{m})$ \\
\hline 250 & 0.0008 \\
400 & 0.0017 \\
500 & 0.0026 \\
1000 & 0.006 \\
\hline
\end{tabular}

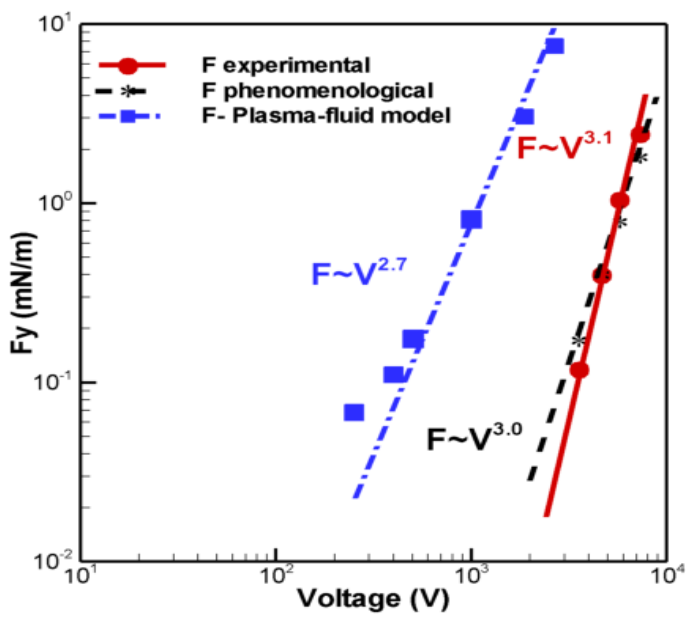

Figure 15. $F_{y, a v g}$ power-law dependence on voltage is compared for two different numerical modelsphenomenological and the first principle-based plasma fluid model along with experimental data of [17].

The arrows point to the set of axes chosen for each of the curves.

The force shows a power-law dependence on the applied voltage. In Figure 15 three different force measurements are compared for their voltage. The experimental (work of Van Dyken et al.[17]) and the phenomenological model data are the same used in our earlier study [5] and use air as the modeling fluid. In order to compare with the experiments, the normal force acting on the actuator surface is used for establishing the correlation as against the axial components employed so far. It can be seen that phenomenological and the experimental measurements have one common data point which is employed to close the model. The remaining data points are predicted with reasonable accuracy by the linear field or phenomenological approach with a dependence of $\mathrm{V}^{3.0}$ as against the $\mathrm{V}^{3.1}$ dependence from the experiment [17]. The first-principles/hydrodynamic plasma model for Helium shows a $\mathrm{V}^{2.7}$ power-law for the force generation. The difference can be attributed to the different species dynamics between the Helium and air chemistry as well as the choice of voltage regime employed. Overall, it is worth noting that this power-law behavior is desirable for enhancing the actuator operating range. 


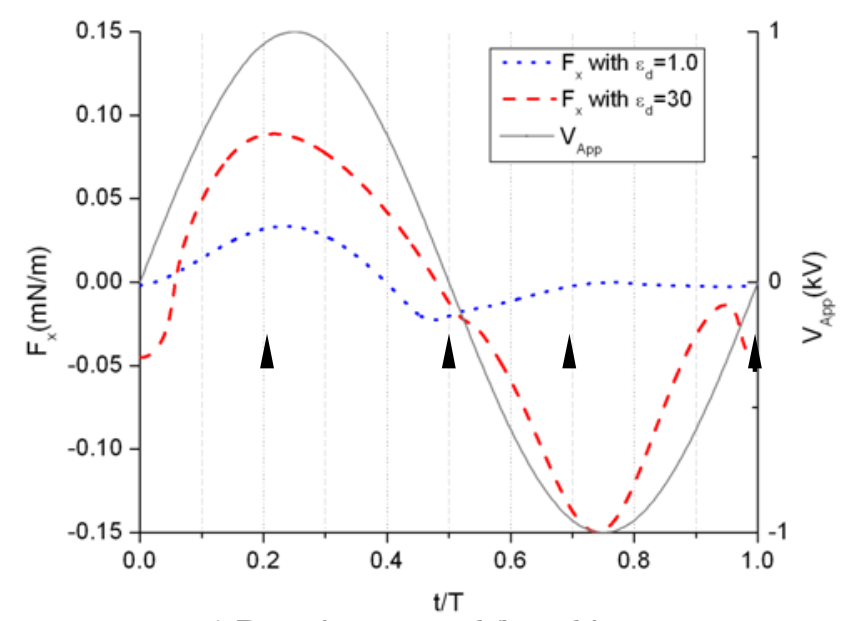

a) Domain-averaged force history
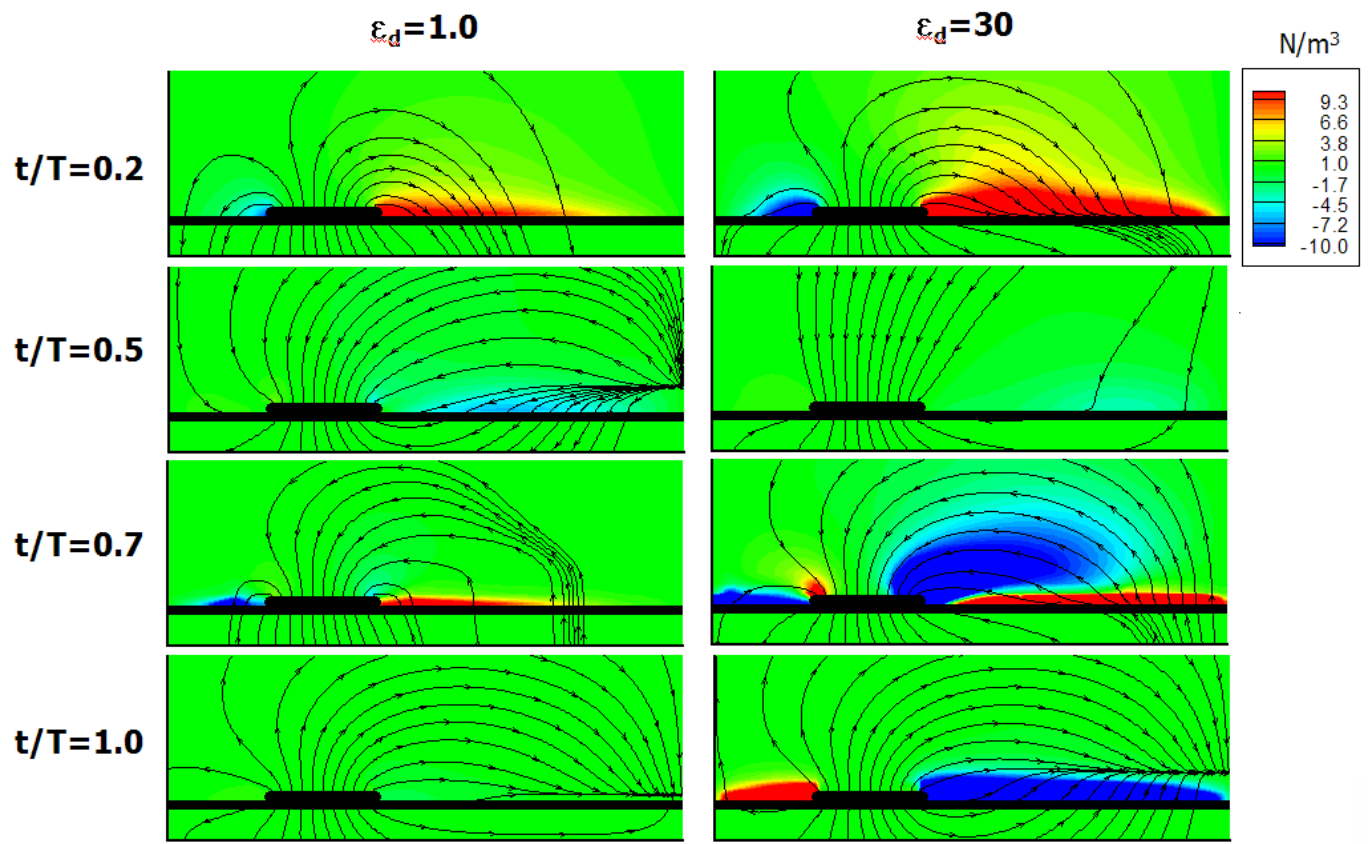

b) $F_{x}$ contour and electric field lines

Figure 16. Effect of dielectric constant $(20 \mathrm{kHz}, 1 \mathrm{kV})$ : force evolution

\section{Effect of Material Property (dielectric constant)}

To investigate the effect of the dielectric constant on force generation, several cases are modeled. Some materials used in the various studies are presented in Table 7 . In this study the dielectric constant is varied as 1, 4.5 and 30, which may not have corresponding materials but convey some insights of the effect of the constant. 


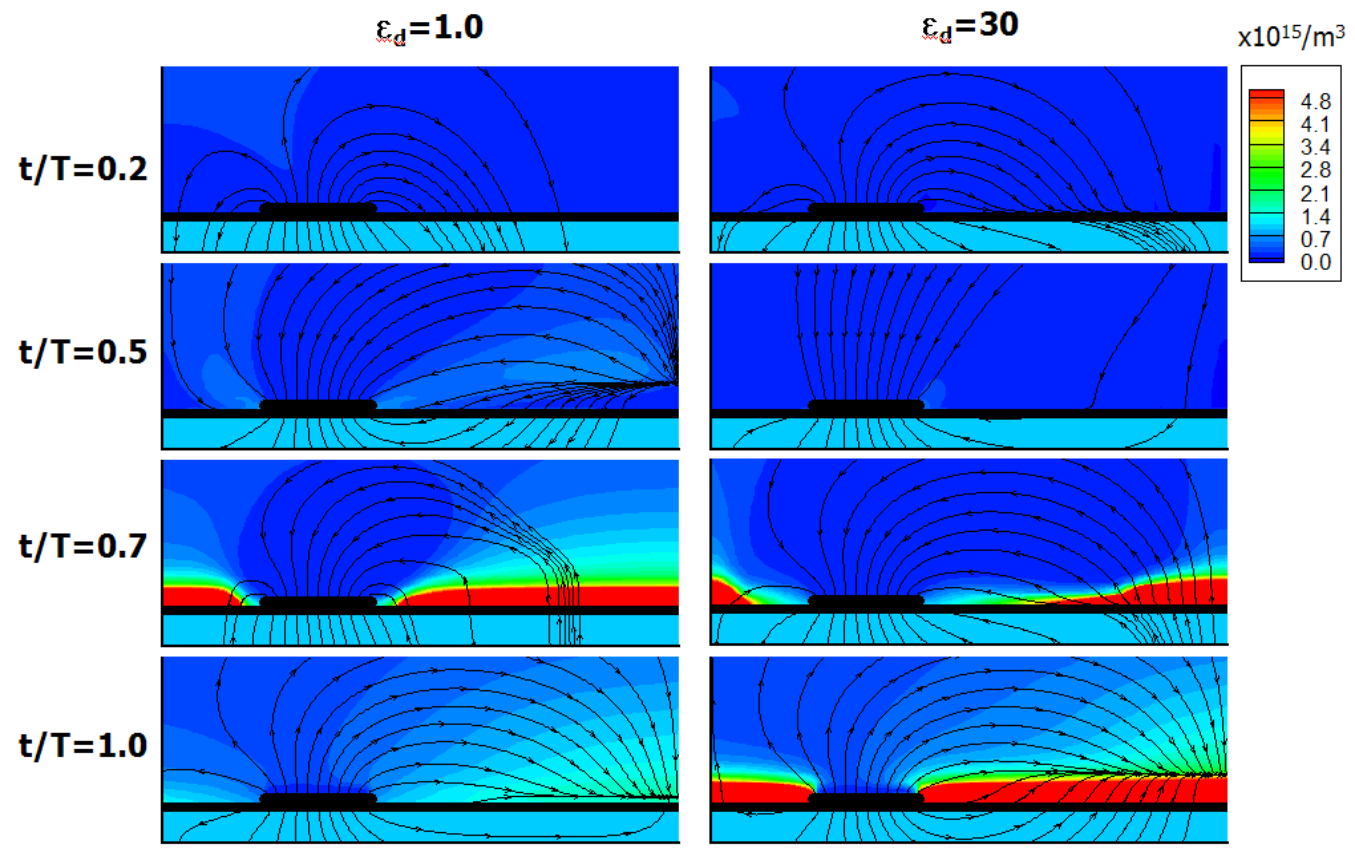

a) Electron number density contour and electric field lines

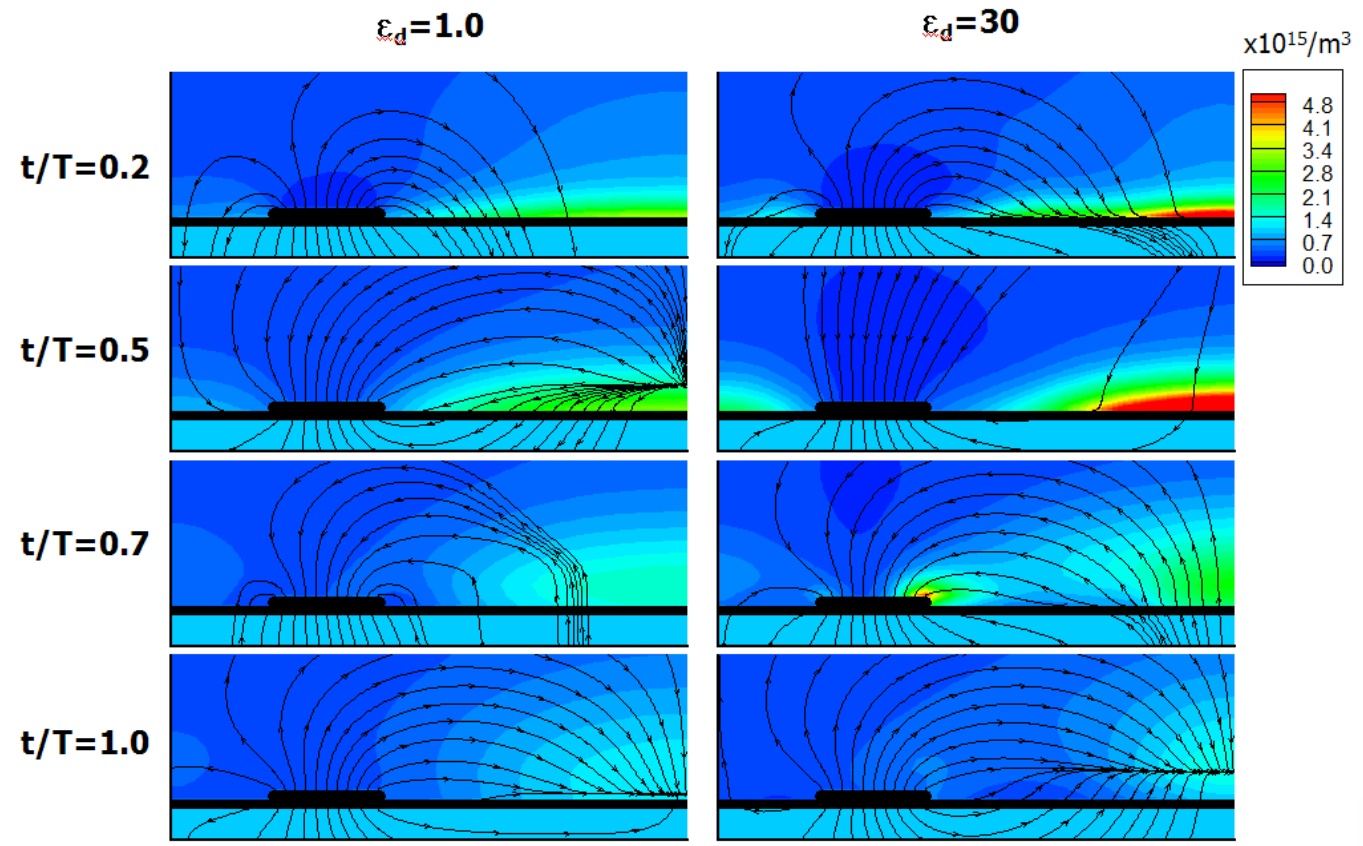

b) Ion number density contour and electric field lines

Figure 17. Effect of dielectric constant $(20 \mathrm{kHz}, 1 \mathrm{kV})$ : Species evolution

Table 7. Dielectric constant of materials (at $25^{\circ} \mathrm{C}, 10 \mathrm{kHz}$ )

\begin{tabular}{l|cccccc}
\hline Material & Air & $\begin{array}{c}\text { Plasticell [42] } \\
\text { (polyvinyl } \\
\text { chloride) }\end{array}$ & $\begin{array}{c}\text { Glass-epoxy } \\
\text { [43] }\end{array}$ & Alumina & $\begin{array}{c}\text { Thallium } \\
\text { bromide } \\
{[\mathbf{4 2}]}\end{array}$ & $\begin{array}{c}\text { Barium } \\
\text { titanite }\end{array}$ \\
\hline $\begin{array}{l}\text { Dielectric } \\
\text { constant }\end{array}$ & 1.00054 & 1.04 & 5.2 & 10 & 30.3 & 1200 \\
\hline
\end{tabular}


There are some different features in the result of different dielectric constant. In Figure 16a), there is higher concentration of negative force at $\mathrm{t} / \mathrm{T}=0.7$ for $\varepsilon_{\mathrm{d}}=30$, which is absent for $\varepsilon_{\mathrm{d}}=1.0$. These phenomena are related to the deformation of electric field line, increased electric field strength which will be shown in the later part especially near the wall surface, and the difference in the charged particle movement affected by them.

From the electron and ion number density contours of Figure 17c) and d), it can be identified that the concentration of ions near the upper electrode is prominent for higher $\varepsilon_{\mathrm{d}}$ which corresponds to the same region where the minimum negative force is generated in the second half cycle. And though the accumulation of electrons on the dielectric surface continues the second half cycle, there is a unique point of time at which the accumulated electron layer reaches to the upper electrode and those accumulated particles create a pseudo-electrode on the surface with significant change in electric field lines.

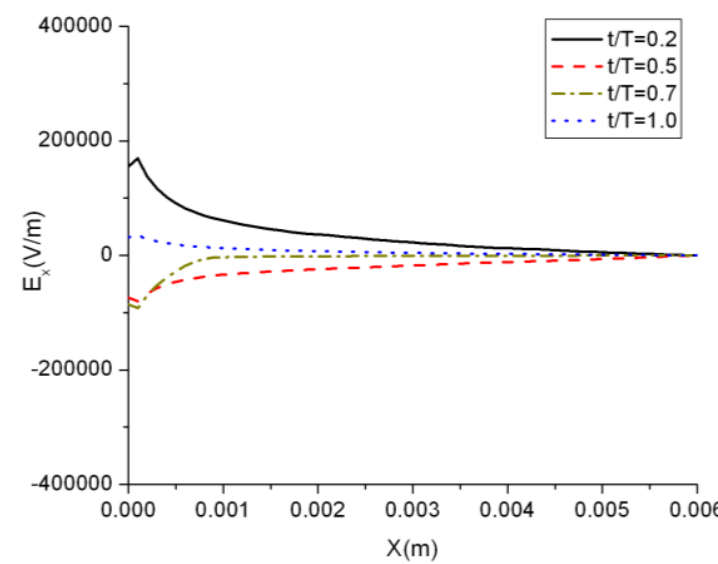

a) $\varepsilon_{\mathrm{d}}=1.0$

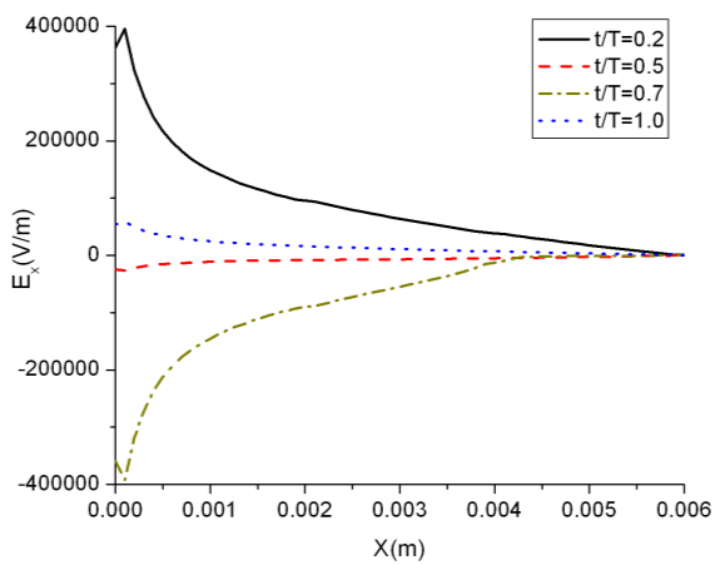

b) $\varepsilon_{d}=30$

Figure 18. $\mathrm{E}_{\mathrm{x}}$ along the dielectric surface

Figure 18 shows the $\mathrm{x}$-directional electric field strength, $\mathrm{E}_{\mathrm{x}}$ along the surface which starts from the right end of the upper electrode. The comparison of two cases indicates the higher dielectric constant results in the higher value and steeper slope in the distribution of $\mathrm{E}_{\mathrm{x}}$. The higher the constant means increase in the polarization tendency of the material and thus decreased electric potential near the wall. This phenomenon for higher dielectric constant causes lower potential on the dielectric surface apart from the upper electrode and higher strength and steeper slope in electric field, especially $E_{x}$ near the wall as a result. This effect is prominent when the applied voltage reaches positive and negative peaks at which the effect of charged particles on the electric field is weak. The magnitude of $\mathrm{E}_{\mathrm{x}}$ is closely related to the generation of charged particles as well as instantaneous force generation. The higher peak value near the electrode $(x=0)$ at $t / T=0.7$ in the case of $\varepsilon_{d}=30$ explains the distinctive ion generation in this region mentioned above. In Figure 18b), the flat part of $\varepsilon_{\mathrm{d}}=30$ case at $\mathrm{t} / \mathrm{T}=0.7$ which starts from $\mathrm{x}=0.0042$ to the end of the domain corresponds to the length of the electron layer spread at that time which eliminates the electric potential difference in the region. And this effect does not exist explicitly for the ion accumulation which prevails over the former half cycle.

\section{Conclusion}

A combined hydrodynamics and plasma dynamics model in the context of a discharge-induced thermofluid transport is presented. This provides a way of self-consistent modeling of the discharge effects as opposed to an analytical-empirical model previously presented in [1]. The two-dimensional helium dielectric barrier discharge in an asymmetric geometry has been modeled using a finite volume operator-split sequential approach to efficiently solve the multi-scale problem. The two-species plasma simulations revealed that the generation of the unidirectional momentum coupling is primarily affected by the combination of factors such as the asymmetry of the geometric arrangement, the waveform of the applied voltage, the species mobility and dielectric material.

Overall characteristics of the plasma dynamics

There are two different processes in the two half-cycles of the actuator operation, largely due to the difference in mobility between faster electrons and slower ions, and the geometric configurations of the 
DBD/electrodes. The first half-cycle is characterized by the deposition of the slower ion species on the insulator surface while the second half-cycle by the deposition of the electrons at a faster rate. Regarding the various actuator parameters, the following observations can be summarized.

Impact of lower electrode size

The increased lower electrode size provides the larger area available for the deposition of charged particles which also results in the increase of the peak values of the time-varying force.

Impact of waveform

Introducing positive and negative sawtooth waveforms affects the rate of change in particle number densities and force history, but it does not increase the resultant average force. Specifically, the study indicates that the rate of applied voltage variation and the duration of the polarity, both play a role in the net force generation.

Impact of voltage

The sensitivity of the generated force to the magnitude of the applied voltage for a sinusoidal (symmetric) waveform shows a near cubic ( 2.7) dependence for the first-principles hydrodynamic model in Helium gas. This is in the region of the observed experimental dependency for air which is $\sim 3.1$ and the phenomenological model ( $\sim 3.0)$. Impact of frequency

The frequency of the applied voltage interplays with physical length scales-electrode size and spacing- of the actuator and the mobility of each particle species, determining the time allowed for particles to deposit on or release from the dielectric surface. This especially affects the polarity reversal phases in each cycle, resulting in the increased asymmetry of waveform and averaged force with the lower frequency.

Effect of material property - dielectric constant

The change in the dielectric constant of the insulator mainly affects the electric field near its surface which determines the degree of ionization and deposition of charged particles. Although the increased dielectric constant produces higher peaks in each half cycle of time-varying force, the resultant average force decreases mainly due to the decrease in overall asymmetry of the waveform.

The effect of frequency is found to be modest as compared to the sensitivity to the applied voltage which shows a power-law dependence on the voltage for the measure force in the domain. This relationship shows substantial similarity to the experimental measurements and the phenomenological model. The strong power-law dependence of the force on the voltage is significant for realizing large momentum effects and maintaining a wide range of operating conditions.

It seems that there are two conditions to obtain higher axial force which is delivered to the neutral fluid increasing the peak value of the cyclic force generation and introducing more asymmetry to the first and second half of the cycle to make the positive part more prominent. Although various parameters are coupled and correlated to each other, the increase in the lower electrode size, applied voltage and dielectric constant tend to contribute to the first factor, and the decrease in frequency of applied voltage tend to contribute to the second factor. To generate higher force these parameters including others need to be adequately tuned to accomplish those conditions.

Acknowledgment

The present work has been supported in part by the Air Force Research Laboratory, Flight Vehicle Directory, under the Collaborative Center in Aeronautical Science project, Dr. Jack Benek program monitor.

\section{References}

1. Shyy, W., Jayaraman, B., and Anderson, A., "Modeling of glow-discharge induced flow dynamics", J. Appl. Phys., 92(11), pp 6434-6443, 2002.

2. Roth, J.R., Sherman, D.M., and Wilkinson, S.P., "Boundary layer flow control with a one atmosphere uniform glow discharge", AIAA paper 98-0328, $36^{\text {th }}$ AIAA Aerospace Sciences Meeting and Exhibit, Reno, NV, Jan. 12-15, 1998.

3. Corke, T.C., Jumper, E.J., Post, M.L., Orlov. D., and Mclaughlin, T.E., "Application of weakly-ionized plasmas as wing flow-control devices", AIAA paper 2002-0350, $41^{\text {st }}$ Aerospace Sciences Meeting and Exhibit, Reno, NV, Jan. 6-9, 2003.

4. Enloe, C.L., Mclaughlin, T.E., Van Dyken, R., and Kachner, K.D., "Mechanisms and responses of a single dielectric barrier plasma actuator: Plasma Morphology", AIAA J. 42(3), pp. 589-594, 2004.

5. Jayaraman, B., and Shyy, W., "Flow control and thermal management using dielectric glow discharge concepts", AIAA paper 2003-3712, $33^{\text {rd }}$ AIAA Fluid Dynamics Conference and Exhibit, Orlando, Jun 23-26, 2003.

6. Jayaraman, B., Thakur, S., and Shyy, W., "Modeling of dielectric barrier discharge and resulting fluid dynamics", AIAA paper 2006-0686, 44 ${ }^{\text {th }}$ Aerospace Sciences Meeting and Exhibit, Reno, NV, Jan 9-12, 2006. 
7. Jayaraman, B., Thakur, S., and Shyy, W., "Modeling of fluid dynamics and heat transfer induced by dielectric barrier plasma actuator", J. Heat. Trans., 129(4), pp. 517-525, 2007.

8. Patel, M.P., Sowle, Z.H., Corke, T.C., and He,C., "Autonomous sensing and control of wing stall using a smart plasma slat", AIAA paper 2006-1207, $44^{\text {th }}$ Aerospace Sciences Meeting and Exhibit, Reno, NV, Jan. 9-12, 2006.

9. Thomas, F.O., Kozlov, A. and Corke,T.C., "Plasma actuators for landing gear noise reduction", AIAA paper 2005-3010, 11th AIAA/CEAS Aeroacoustics Conference (26th AIAA Aeroacoustics Conference), Monterey, California, May 23-25, 2005.

10. Poggie, J., "Plasma-based hypersonic flow control", AIAA paper 2006-3567, 37th AIAA Plasmadynamics and Lasers Conference, San Francisco, CA, Jun. 5-8, 2006.

11. Poggie, J. "Plasma-based control of shock-wave/boundary-layer interaction", AIAA paper 2006-1007, 44 Aerospace Sciences Meeting and Exhibit, Reno, NV, Jan. 9-12, 2006.

12. Singh, K.P., Roy, S., and Gaitonde, D.V., "Modeling of dielectric barrier discharge plasma actuator with atmospheric air chemistry", AIAA paper 2006-3381, 37th AIAA Plasmadynamics and Lasers Conference, San Francisco, CA, Jun. 5-8, 2006.

13. Yuan, X. and Raja,L.L., "Computational study of capacitively coupled high-pressure glow discharges in helium", IEEE Transactions on Plasma Science, 31(4), pp.495-503, 2003.

14. Roth, J.R., Madhan, R.C.m.,Yadav, M.,Rahel, J. and Wilkinson, S.P., "Flow field measurements of paraelectric, peristaltic, and combined plasma actuators based on one atmosphere uniform glow discharge plasma," AIAA Paper, 2004-845 42nd AIAA Aerospace Sciences Meeting and Exhibit, Reno, NV, Jan. 5-8, 2004.

15. Roy, S., Singh, K.P., Kumar, H., Gaitonde, D.V. and Visbal, M., "Effective discharge dynamics for plasma actuators", AIAA paper 2006-374, 44 ${ }^{\text {th }}$ Aerospace Sciences Meeting and Exhibit, Reno, NV, Jan. 9-12, 2006.

16. Corke, T.C., and Post, M.L., "Overview of plasma flow control: concepts, optimization and applications", AIAA paper 2005-0563, $43^{\text {rd }}$ Aerospace Sciences Meeting and Exhibit, Reno, NV, Jan. 10-13, 2005.

17. Van Dyken, R., Mclaughlin, T.E., and Enloe, C.L., "Parametric investigations of a single dielectric barrier plasma actuator", AIAA paper 2004-846, 42 ${ }^{\text {nd }}$ Aerospace Sciences Meet and Exhibit, Reno, NV, Jan. 5-8, 2004.

18. Roth, J.R. and Dai, X, "Optimization of the Aerodynamic plasma actuator as an electrohydrodynamic (EHD) electrical device", AIAA paper 2006-1203, 44 ${ }^{\text {th }}$ Aerospace Sciences Meeting and Exhibit, Reno, NV, 2006.

19. Pons, J, Moreau, E and Touchard, G, "Asymmetric surface dielectric barrier discharge in air at atmospheric pressure: electrical properties and induced airflow characteristics", J. Phys. D:Appl.Phys., 38, pp. 3635-3642, 2005.

20. Smith, B.L., and Glezer, A., "The formation and evolution of synthetic jets," Physics of Fluids, 10(9), pp. 22812297, 1998.

21. Corke, T.C., and Matlis, E., "Phased plasma arrays for unsteady flow control", AIAA paper 2000-2323, Fluids 2000, Denver, CO, June 19-22, 2000.

22. Post, M.L., and Corke, T.C., "Separation control on high angle of attack airfoil using plasma actuators", AIAA paper 2003-1024, 41 ${ }^{\text {st }}$ Aerospace Sciences Meet and Exhibit, Reno, NV, Jan 6-9, 2003.

23. Chan, S., Zhang, X. and Gabriel, S., "The attenuation of cavity tones using plasma actuators", AIAA paper 2005-2802, $11^{\text {th }}$ AIAA/CEAS Aeroacoustics Conference, Monterey, CA, May 23-25, 2005.

24. Soldati, A., and Banerjee, S., "Turbulence modification by large-scale organized electro-hydrodynamic flows", Phys. of Fluids, 10(7), pp 1742-1756, 1998.

25. Segur, P., and Massines, F., "The role of numerical modeling to understand the behavior and to predict the existence of an atmospheric pressure glow discharge controlled by a dielectric barrier", Proc. Of the XIII ${ }^{\text {th }}$ Int. Conf. of Gas Discharges and their applications, Glasgow, Sep. 3-8, pp. 15-24, 2000.

26. Gaitonde, D.V., Visbal, M.R., and Roy, S., "Control of flow past a wing section with plasma-based body forces", AIAA paper 2005-5302, 36 ${ }^{\text {th }}$ Plasmadynamics and Lasers Conference, Toronto, Jun. 6-9, 2005.

27. Riley, M.E., Greenberg, K.E., Hebner, G.A., and Drallos, P., "Theoretical and experimental study of lowtemperature, capacitiviley coupled, radio-frequency helium plasmas", J. Appl. Phys, 75(6), pp. 2789-2798, 1994.

28. Nitschke, T.E., and Graves, D.B., "A comparison of particle in cell and fluid model simulations of low-pressure radio frequency discharges", J. Appl. Phys. 76(10), pp. 5646-5660, 1994.

29. Kushner, M.J.," "Mechanisms for power deposition in Ar/SiH4 capacitively coupled RF discharges", IEEE Trans. Plasma Sci., 14(4), pp. 188, 1986.

30. Massines, F., Ben Gadri, R., Rabehi, A., Decomps, Ph., Segur, P., and Mayoux, Ch., "Experimental and theoretical study of a glow discharge at atmospheric pressure controlled by dielectric barrier", J. Appl. Phys, 83(6), pp. 2950-2957, 1998.

31. Ben Gadri, R., "One atmospheric glow discharge structure revealed by computer modeling," IEEE Trans. Plasma Sci., 27(1), pp. 36-37, 1999. 
32. Hammond, E.P., Mahesh, K., and Moin, P., "A numerical method to simulate radio-frequency plasma discharges", J.Comp. Phys., 176, pp 402-429, 2002.

33. Colella, P., Dorr, M.R., and Wake, D.D., "Numerical solution of plasma fluid equations using locally refined grids", J. Comp. Phys. 152, pp. 550-583, 1999.

34. Colella, P., Dorr, M.R., and Wake, D.D., "A conservative finite difference method for the numerical solution of plasma fluid equations", J. Comp. Phys. 149, pp. 168-193, 1999.

35. Roy, S., and Gaitonde, D.V., "Modeling surface discharge effects of atmospheric RF on gas flow control", AIAA paper 2005-0160, $43^{\text {rd }}$ AIAA Aeropsace Sciences Meeting and Exhibit, Reno, NV, Jan. 10-13, 2005.

36. Roy, S., and Gaitonde, D.V., "Multidimensional collisional dielectric barrier discharge for flow separation control at atmospheric pressures", AIAA paper 2005-4631, 35 ${ }^{\text {th }}$ AIAA Fluid dynamics conference, Toronto, Canada, 6-9 June, 2005.

37. Singh, K.P., and Roy, S., "Simulation of an asymmetric single dielectric barrier plasma actuator", J. App. Phys. 98, 083303-1, 2005.

38. Shyy, W., Thakur, S., Ouyang, H., Liu, J., and Blosch, E., Computaional Techniques for Complex Transport Phenomena, Cambridge university press, UK, 1997.

39. Thakur, S., Wright, J., and Shyy, W., STREAM: A computational fluid dynamics and heat transfer NavierStokes solver: theory and applications, Gainesville, FL: Streamline Numerics, Inc; 2002

40. Verwer, J.G., "Explicit Runge-Kutta methods for parabolic partial differential equations", Appl. Numer. Math. 22, pp. 359-379, 1996.

41. Cohen, S.D., and Hindmarsh, A.C., “CVODE, a stiff/nonstiff ODE solver in C”, Comp.Phys. 10 (2), pp. 138143, 1996.

42. Von Hippel, A. R. Dielectric Materials and Applications, The Technology Press of MIT, pp. 294-370, 1954.

43. Abe, T., Takizawa, Y., Sato, S., "A parametric experimental study for momentum transfer by plasma actuator", AIAA paper 2007-0187, 45 ${ }^{\text {th }}$ Aerospace Sciences Meeting and Exhibit, Reno, NV, Jan 8-11, 2007. 